\title{
The lactase persistence genotype is a protective factor for the metabolic syndrome
}

\author{
Deise C. Friedrich ${ }^{1}$, Fabiana M de Andrade ${ }^{2}$, Marilu Fiegenbaum ${ }^{3}$, Silvana de Almeida ${ }^{3}$, Vanessa S. \\ Mattevi $^{3}$, Sidia M. Callegari-Jacques ${ }^{4}$ and Mara H. Hutz ${ }^{1}$ \\ ${ }^{1}$ Departamento de Genética, Universidade Federal do Rio Grande do Sul, Porto Alegre, RS, Brazil. \\ ${ }^{2}$ Instituto de Ciências da Saúde, Universidade Feevale, Novo Hamburgo, RS, Brazil. \\ ${ }^{3}$ Pós-Graduação em Ciências da Saúde, Universidade Federal de Ciências da Saúde de Porto Alegre, \\ Porto Alegre, RS, Brazil. \\ ${ }^{4}$ Departamento de Estatística, Universidade Federal do Rio Grande do Sul, Porto Alegre, RS, Brazil.
}

\begin{abstract}
The Metabolic Syndrome (MetS) is defined as a pattern of metabolic disturbances, which include central obesity, insulin resistance and hyperglycemia, dyslipidemia, and hypertension. Milk has been promoted as a healthy beverage that can improve the management of MetS. Most human adults, however, down-regulate the production of intestinal lactase after weaning. Lactase encoded by the LCT gene is necessary for lactose digestion. The -13910C > T SNP (rs4988235) is responsible for the lactase persistence phenotype in European populations. We herein investigated whether the lactase persistence genotype is also associated with the MetS in subjects from a Brazilian population of European descent. This study consisted of 334 individuals (average age of 41 years) genotyped by PCR-based methods for the $-13910 \mathrm{C}>\mathrm{T}$ SNP. Clinical data were assessed and the genotypes were tested for their independent contribution to the MetS using chi-square tests and multiple logistic regression analysis. Univariate analyses showed that hypertension and MetS prevalence were higher in individuals with the lactase non-persistence genotype than in lactase persistence subjects. Furthermore, lactase persistence was associated with a lower risk for MetS $(\mathrm{OR}=0.467 ; 95 \% \mathrm{Cl} 0.264-0.824 ; \mathrm{p}=0.009)$. These results suggest that $L C T$ genotypes can be a valuable tool for the management of MetS treatment.
\end{abstract}

Keywords: metabolic syndrome, lactase persistence, hypolactasia, lactose.

Received: March 25, 2014; Accepted: July 15, 2014.

\section{Introduction}

The metabolic syndrome (MetS) has been defined as a cluster of metabolic risk factors, which include central obesity, hypertension, dyslipidemia, insulin resistance and hyperglycemia. It is predictive of an increased risk of type2 diabetes and cardiovascular disease (CVD) (Expert Panel on Detection, Evaluation, and Treatment of High Blood Cholesterol in Adults, 2001; Després and Pérusse, 2008).

In observational studies, dairy product consumption was inversely associated with the occurrence of one or more individual components of the MetS, thus representing a protective effect of milk against MetS (Elwood et al., 2007; Pfeuffer and Schrezenmeir, 2007) and also against high blood pressure (FitzGerald et al., 2004). A possible explanation for these results was that dairy product intake may be associated with other healthy dietary habits or

Send correspondence to Mara H. Hutz. Departamento de Genética, Universidade Federal do Rio Grande do Sul, Caixa Postal 15053, 91501-970 Porto Alegre, RS, Brazil. E-mail: mara.hutz@ufrgs.br. health promoting lifestyles (Pfeuffer and Schrezenmeir, 2007). Only one study reported that women who never drank milk had lower insulin resistance scores, lower triglyceride levels and body mass index (BMI), higher highdensity lipoprotein (HDL) and cholesterol levels, and they also suffered less frequently from diabetes than those who drank milk (Pfeuffer and Schrezenmeir, 2007).

Most human adults down-regulate the production of intestinal lactase after weaning. Lactase is necessary for the digestion of lactose, the main carbohydrate in milk, and without it, milk consumption can lead to bloating, flatulence, cramps and nausea (Swallow, 2003). Lactase, secreted by small-intestinal enterocytes, is encoded by the LCT gene (OMIM \#603202) which maps in 2q21 (Kruse et al., 1988). A C to T transition SNP (rs4988235) located within an intronic sequence of the MCM6, which is the upstream adjacent gene, acts as an enhancer for lactase expression in vitro and is responsible for the lactase persistence (LP) phenotype in European populations. The $\mathrm{CC}$ genotype determines the lactase non-persistence phe- 
notype (LNP), also known as adult-type hypolactasia (Enattah et al., 2002). Other polymorphisms in the same enhancer region or in its vicinity were also related to the LP phenotype in populations from East Africa and the Middle East (Ingram et al., 2007; Tishkoff et al., 2007; Torniainen et al., 2009). Lactase persistent individuals are usually lactose tolerant and, hence, they can consume milk and dairy products without symptoms.

The LP predicted phenotype (-13910 CT and TT genotypes) was detected in $51 \%$ of southern Brazilian individuals of European ancestry. No other variant in the enhancer region was identified in this population by sequencing (Friedrich et al., 2012). In an attempt to further explore the complex genetic component of the metabolic syndrome, we evaluated whether the LP allele of the $L C T$ SNP (rs4988235) would be associated with MetS.

\section{Subjects and Methods}

\section{Study subjects}

A total of 334 subjects of European ancestry, as ascertained by skin color and morphological characteristics, most of them of low socio-economic status, were included in this investigation. Lactase persistence allele frequency, clinical, demographic and laboratory variables from this sample have been fully described elsewhere (Mattevi et al., 2002; Fiegenbaum et al., 2007; Friedrich et al., 2012). Pregnant women, as well as those individuals with secondary hyperlipidemia due to renal, liver and/or thyroid disease were not invited to participate in the study. For all patients enrolled, a questionnaire was completed by an interviewer that included details on medicine intake and lifestyle variables such as smoking, physical activity, alcohol consumption, oral contraceptive usage, and menopause status. The Ethics Committee of the Federal University of Rio Grande do Sul approved the study protocol. All participants of the study were able to read the informed consent form and gave written informed consent.

Blood samples were collected after $12 \mathrm{~h}$ fasting. Total cholesterol (TC), triglyceride (TG) and glucose concentrations were determined by conventional enzymatic methods, on a Mega Merck Analyzer (Merck Darmstadt, Germany). HDL cholesterol was determined with a selective immunoseparation-based homogenous assay, followed by colorimetric quantification. LDL cholesterol was calculated according to Friedewald et al. (1972). Waist circumference was measured at mid-concentration between the lower rib margin and the iliac crest (World Heatlh Organization, 1997). Body mass index (BMI) was calculated as weight in $\mathrm{kg}$ divided by square height in meters $\left(\mathrm{kg} / \mathrm{m}^{2}\right)$. Genomic DNA extraction and genotyping procedures were as previously described (Friedrich et al., 2012)

\section{Definition of the metabolic syndrome}

In this investigation the International Diabetes Federation (IDF) definition for the MetS was employed (International Diabetes Federation, 2005). Inclusion criteria were: waist circumference $\geq 94 \mathrm{~cm}$ for men and $80 \mathrm{~cm}$ for women, plus two of the following factors: 1) HDL-cholesterol $<40 \mathrm{mg} / \mathrm{dL}$ for men and $<50 \mathrm{mg} / \mathrm{dL}$ for women, or specific treatment for this lipid abnormality; 2) triglycerides $\geq 150 \mathrm{mg} / \mathrm{dL}$ or specific treatment for this lipid abnormality; 3) fasting glycaemia $\geq 100 \mathrm{mg} / \mathrm{dL}$, or previously diagnosed type 2 diabetes; 4) blood pressure $\geq 130 / 85 \mathrm{mmHg}$, or treatment of previously diagnosed hypertension.

\section{Statistical analysis}

Differences between means were estimated by Student's $t$-test and Mann-Whitney U-test when there was a deviation from normal distribution. Chi-square analysis was performed for categorical variables. Logistic regression was used to assess the effect of the $L C T$ polymorphism on the occurrence of MetS. Gender, age, BMI, and physical activity (dichotomous variable, sedentary or not) were included in the model as confounders, as they are biologically involved in MetS development. All analyses were performed using SPSS version 18 software. Two sided p-values $<0.05$ were considered as statistically significant.

\section{Results}

Demographic and clinical characteristics of the investigated sample are presented in Table 1, stratified by $L C T$ $-13910 \mathrm{C}>\mathrm{T}$ genotypes. Univariate analyses for the lactase persistence genotype in a dominant model are shown in Table 1. The non-persistence genotype (CC) was associated with a higher prevalence of hypertension $(22.7 \%)$ when compared to the lactase persistence genotypes (CT+TT) $(13.4 \% ; p=0.032)$. The other components of MetS did not differ among groups. The prevalence of MetS was higher in individuals with the lactase non-persistence genotype $(34.3 \%)$ than in lactase persistence subjects $(21.6 \%$; $\mathrm{p}=0.01)$

Multiple logistic regression analysis was performed for the association between the $L C T$ polymorphism and MetS presence, controlling for gender, age, BMI and physical activity. Age and BMI remained in the final model as MetS risk factors ( $\mathrm{p}<0.001$ for both), whereas lactase persistence was associated with a lower risk $(\mathrm{OR}=0.467 ; 95 \%$ CI 0.264-0.824; $\mathrm{p}=0.009$, Table 2).

\section{Discussion}

The metabolic syndrome plays an important role as a predictor for increased risk of type-2 diabetes and cardiovascular disease. Any tools that potentially help the management of the MetS provide important benefits for health. 
Table 1 - Demographic, laboratory and clinical characteristics of the investigated sample stratified by genotype.

\begin{tabular}{|c|c|c|c|}
\hline \multirow[b]{2}{*}{ Variables } & \multicolumn{2}{|c|}{ Genotypes } & \multirow[b]{2}{*}{ p-value } \\
\hline & $\mathrm{CC}$ & $\mathrm{CT}+\mathrm{TT}^{\mathrm{a}}$ & \\
\hline Total number & 163 & 171 & \\
\hline Age (years) & $40.6 \pm 14.6$ & $42.3 \pm 15.6$ & $0.444^{\mathrm{b}}$ \\
\hline Gender ( $\%$ of male $)$ & 47.9 & 46.8 & $0.913^{\mathrm{b}}$ \\
\hline Waist circumference $(\mathrm{cm})$ & $92.1 \pm 13.6$ & $89.9 \pm 11.9$ & $0.127^{\mathrm{c}}$ \\
\hline Total cholesterol (mg/dL) & $199.1 \pm 45.2$ & $198.2 \pm 42.9$ & $0.902^{\mathrm{b}}$ \\
\hline HDL- cholesterol (mg/dL) & $44.1 \pm 10.9$ & $44.1 \pm 12.4$ & $0.798^{\mathrm{b}}$ \\
\hline LDL- cholesterol (mg/dL) & $125 \pm 37.9$ & $127.3 \pm 38$ & $0.711^{\mathrm{b}}$ \\
\hline Triglycerides (mg/dL) & $146 \pm 111.1$ & $131.2 \pm 85.2$ & $0.418^{\mathrm{b}}$ \\
\hline Glycaemia (mg/dL) & $97.7 \pm 30.7$ & $92.7 \pm 25.3$ & $0.081^{\mathrm{b}}$ \\
\hline Hypertension (\% of hypertensive individuals) & 22.7 & 13.4 & $0.032^{*, \mathrm{~d}}$ \\
\hline Physical activity (\% of sedentary individuals) & 66 & 61.2 & $0.356^{\mathrm{d}}$ \\
\hline Body mass index $\left(\mathrm{kg} / \mathrm{m}^{2}\right)$ & $26.4 \pm 5.13$ & $26 \pm 4.34$ & $0.333^{\mathrm{b}}$ \\
\hline Metabolic syndrome (\%) & 34.3 & 21.6 & $0.01^{*, \mathrm{~d}}$ \\
\hline
\end{tabular}

*Statistically significant.

${ }^{\mathrm{a}} \mathrm{CT}$ and TT genotypes were grouped because carriers of the $-13910 * \mathrm{~T}$ allele have the predicted lactase persistence phenotype.

${ }^{\mathrm{b}}$ Mann-Whitney U-test.

'Student's $t$-test.

${ }^{\mathrm{d}}$ Chi-square test.

Table 2 - Logistic regression analysis predicting the Metabolic Syndrome.

\begin{tabular}{lccc}
\hline & OR & $95 \% \mathrm{CI}$ & p-value \\
\hline LP genotype & 0.467 & $0.26-0.82$ & 0.009 \\
Age & 1.049 & $1.03-1.07$ & $<0.001$ \\
Body mass index & 1.247 & $1.16-1.33$ & $<0.001$ \\
\hline
\end{tabular}

In this study we reported that lactase persistent individuals presented a lower risk to develop MetS.

Association studies between LP genotypes and MetS or its single components are scarce. Most investigations focused on BMI. Lamri et al. (2013) observed that the LP genotype was associated with a lower risk of MetS in a low dairy product consumer group, even after adjusting for BMI. MetS was more prevalent in the higher consumer group, but after adjusting for BMI the statistical significance was lost. These investigators suggested that the negative association between LP genotype and MetS in the low consumer group seemed more consistent than the positive one. Fumeron et al. (2011) reported that the LP genotype was associated with lower BMI and lower frequency of BMI-related metabolic diseases. However, the LP genotype was also associated with higher BMI in cross-sectional studies in European populations (Almon et al., 2010; Kettunen et al., 2010; Corella et al., 2011), and with higher risk of developing MetS (OR = 1.56; Almon et al., 2010). Malek et al. (2013) reported that the LP allele was significantly associated with BMI, fat mass, and waist circumference in children. The inconsistencies among these studies could be explained by different genetic backgrounds or en- vironmental conditions of the populations studied, given that all investigations were performed with at least moderate-sized samples, and thus probably are not caused by chance alone. Lifestyle components such as differences in smoking habits, physical activity, diet or alcohol consumption may act as modifiers of the effect of gene variants in determining the risk of obesity.

There are plenty of evidences that certain milk components could have a direct benefit for insulin sensitivity, weight, blood pressure, and cholesterol level (Pfeuffer and Schrezenmeir, 2007). The higher intake of calcium could be one of the many possible mechanisms because: a) it could play a critical role in the regulation of energy metabolism; b) it could promote an increased faecal fat excretion by formation of insoluble calcium-fatty acid soaps or by binding of bile acids that impair the formation of micelles (Pfeuffer and Schrezenmeir, 2007); c) it may promote blood pressure reduction (Hajjar et al., 2003); and d) it may decrease oxidative stress and the expression of inflammatory cytokines typically associated with MetS (Zemel and Sun, 2008).

Milk protein-derived peptides are also beneficial. They show hypotensive effects and improve the bioavailability of other minerals and trace elements like magnesium, manganese, zinc, selenium and iron (FitzGerald et al., 2004). In the present study, the prevalence of hypertensive individuals was higher among individuals with the lactase non-persistence genotype.

Almon et al. (2010) showed that high milk consumption is not linked to higher measures of body fat mass in children and adolescents. In the French D.E.S.I.R. cohort 
study, a high consumption of milk and dairy product was associated with lower body weight gain in a 9-year follow-up, and with lower incidence of impaired fasting glycaemia or type 2 diabetes and/or the metabolic syndrome (Fumeron et al., 2011).

The causal relation between LP and MetS could not be determined in the present study. Probably the tolerant individuals consume higher amounts of milk than the intolerant ones, and consequently they have more benefits from this beverage. But, we did not have information about the dietary pattern of the participants of this study, and thus we could not test whether the LP group has higher milk intake than the LNP group.

The genetic approach used is similar to the Mendelian randomisation in which the genetic variant acts as a proxy for the risk factor, in this case, the MetS (Burgess et al., 2012). In this study, the presence of the risk factor ( $L C T$ genotypes) is likely a causal factor for the MetS outcome.

Therapeutic lifestyle changes, including healthy eating habits and weight loss significantly improve most MetS abnormalities (Levesque and Lamarche, 2008). It has been suggested that milk consumption, especially the low-fat milk, as recommended by the DASH (Dietary Approaches to Stop Hypertension) diet is desirable. Moreover, people who consume higher amounts of dairy products also consume higher amount of fiber, fruit, vegetables and whole grains (Azadbakht et al., 2005). Since no dietary data was available for the investigated sample, at present it is not possible to decide if the inverse relation between dairy consumption and MetS observed herein could be attributed to a healthier lifestyle associated with higher intake of dairy or to genotype itself. Also, lactose can modify the intestinal microbiota increasing the total faecal number of bifidobacterium and lactobacilli that are health-promoting bacteria (Francavilla et al., 2012).

The overall results presented in this study should be viewed in the context of certain limitations. The present results were based on predicted phenotypes as we have only genotypes, although the phenotype-genotype correlation for the $-13910 \mathrm{C} / \mathrm{T}$ polymorphism is well established.

Lactase phenotypes can be a valuable tool for the management of MetS during nutrition counseling. However more studies are warranted to confirm and refine the present results as well as to disclose the causal mechanisms of this association.

\section{Acknowledgments}

Thanks are due to Ana Lúcia S. Antunes and Maria Perpétua de O. Pinto from the Clinical Analysis Laboratory of the Pharmacy College and to Gledison Gastaldo from the Biochemical Laboratory of the Clinical Hospital of Porto Alegre. Financial support was provided by Conselho Nacional de Desenvolvimento Científico e Tecnológico (CNPq, Brazil).

\section{References}

Almon R, Alvarez-Leon EE, Engfeldt P, Serra-Majem L, Magnuson A and Nilsson TK (2010) Associations between lactase persistence and the metabolic syndrome in a crosssectional study in the Canary Islands. Eur J Nutr 49:141146.

Azadbakht L, Mirmiran P, Esmaillzadeh A and Azizi F (2005) Dairy consumption is inversely associated with the prevalence of the metabolic syndrome in Tehranian adults. Am J Clin Nutr 82:523-530.

Burgess S, Butterworth A, Malarstig A and Thompson SG (2012) Use of mendelian randomisation to assess potential benefit of clinical intervention. BMJ 345:e7325.

Corella D, Arregui M, Coltell O, Portolés O, Guillem-Sáiz P, Carrasco P, Sorlí JV, Ortega-Azorín C, González JI and Ordovás JM (2011) Association of the LCT-13910C > T polymorphism with obesity and its modulation by dairy products in a Mediterranean population. Obesity 19:17071714.

Després JP and Pérusse L (2008) Genetic and nutritional determinants of the metabolic syndrome: Introduction. J Nutrigenet Nutrigenomics 1:97-99.

Elwood PC, Pickering JE and Fehily AM (2007) Milk and dairy consumption, diabetes and the metabolic syndrome: The Caerphilly prospective study. J Epidemiol Community Health 61:695-698.

Enattah NS, Sahi T, Savilahti E, Terwilliger JD, Peltonen L and Järvelä I (2002) Identification of a variant associated with adult-type hypolactasia. Nat Genet 30:233-237.

Expert Panel on Detection, Evaluation, and Treatment of High Blood Cholesterol in Adults (2001) Executive Summary of The Third Report of The National Cholesterol Education Program (NCEP) Expert Panel on Detection, Evaluation, And Treatment of High Blood Cholesterol In Adults (Adult Treatment Panel III). JAMA 285:2486-2497.

Fiegenbaum M, de Andrade FM and Hutz MH (2007) Association between plasma lipid parameters and APOC3 genotypes in Brazilian subjects: Effect of gender, smoking and APOE genotypes. Clin Chim Acta 380:175-181.

FitzGerald RJ, Murray BA and Walsh DJ (2004) Hypotensive peptides from milk proteins. J Nutr 134:980S-988S.

Francavilla R, Calasso M, Calace L, Siragusa S, Ndagijimana M, Vernocchi P, Brunetti L, Mancino G, Tedeschi G, Guerzoni $\mathrm{E}$, et al. (2012) Effect of lactose on gut microbiota and metabolome of infants with cow's milk allergy. Pediatr Allergy Immunol 23:420-427.

Friedewald NT, Levy RI and Fredrickson DS (1972) Estimation of the concentration of low-density lipoprotein cholesterol in plasma, without use the preparative ultracentrifuge. Clin Chem 18:499-502.

Friedrich DC, Santos SE, Ribeiro-Dos-Santos AK and Hutz MH (2012) Several different lactase persistence associated alleles and high diversity of the lactase gene in the admixed Brazilian population. PLoS One 7:e46520.

Fumeron F, Lamri A, Khalil CA, Jaziri R, Porchay-Baldérelli I, Lantieri O, Vol S, Balkau B and Marre M (2011) Dairy consumption and the incidence of hyperglycemia and the metabolic syndrome: Results from a French prospective study, Data from the Epidemiological Study on the Insulin Resistance Syndrome (DESIR). Diabetes Care 34:813-817. 
Hajjar IM, Grim CE and Kotchen TA (2003) Dietary calcium lowers the age-related rise in blood pressure in the United States: The NHANES III survey. J Clin Hypertens (Greenwich) 5:122-126.

Ingram C, Elamin M, Mulcare C, Weale M, Tarekegn A, Raga T, Bekele E, Elamin F, Thomas M, Bradman N, et al. (2007) A novel polymorphism associated with lactose tolerance in Africa: Multiple causes for lactase persistence? Hum Genet 120:779-788.

Kettunen J, Silander K, Saarela O, Amin N, Müller M, Timpson $\mathrm{N}$, Surakka I, Ripatti S, Laitinen J, Hartikainen AL, et al. (2010) European lactase persistence genotype shows evidence of association with increase in body mass index. Hum Mol Genet 19:1129-1136.

Kruse T, Bolund L, Grzeschik K, Ropers H, Sjöström H, Norén O, Mantei N and Semenza G (1988) The human lactase-phlorizin hydrolase gene is located on chromosome 2. FEBS Lett 240:123-126.

Lamri A, Poli A, Emery N, Bellili N, Velho G, Lantieri O, Balkau B, Marre M and Fumeron F (2013) The lactase persistence genotype is associated with body mass index and dairy consumption in the D.E.S.I.R. study. Metabolism 62:13231329.

Levesque J and Lamarche B (2008) The metabolic syndrome: Definitions, prevalence and management. J Nutrigenet Nutrigenomics 1:100-108.

Malek AJ, Klimentidis YC, Kell KP and Fernandez JR (2013) Associations of the lactase persistence allele and lactose intake with body composition among multiethnic children. Genes Nutr 8:487-494.

Mattevi VS, Zembrzuski VM and Hutz MH (2002) Association analysis of genes involved in the leptin-signaling pathway with obesity in Brazil. Int $\mathrm{J}$ Obes Relat Metab Disord 26:1179-1185.

Pfeuffer M and Schrezenmeir J (2007) Milk and the metabolic syndrome. Obes Rev 8:109-118.

Swallow DM (2003) Genetics of lactase persistence and lactose intolerance. Annu Rev Genet 37:197-219.

Tishkoff S, Reed F, Ranciaro A, Voight B, Babbitt C, Silverman J, Powell K, Mortensen H, Hirbo J, Osman M, et al. (2007) Convergent adaptation of human lactase persistence in Africa and Europe. Nat Genet 39:31-40.

Torniainen S, Parker MI, Holmberg V, Lahtela E, Dandara C and Jarvela I (2009) Screening of variants for lactase persistence/non-persistence in populations from South Africa and Ghana. BMC Genet 10:e31.

World Health Organization (1997) Obesity: Preventing and managing the global epidemic. Geneva: World Health Organization (1988). Report of a WHO consultation on obesity, Geneva, 3-5 June 1997.

Zemel MB and Sun X (2008) Dietary calcium and dairy products modulate oxidative and inflammatory stress in mice and humans. J Nutr 138:1047-1052.

\section{Internet Resources}

International Diabetes Federation (2005) The IDF consensus worldwide definition of the metabolic syndrome. April 14, 2005, http://www.idf.org/webdata/docs/Metac_syndrome_def.pdf (accessed March 20, 2014).

Associate Editor Maria Rita Passos Bueno

License information: This is an open-access article distributed under the terms of the Creative Commons Attribution License, which permits unrestricted use, distribution, and reproduction in any medium, provided the original work is properly cited. 